\title{
New ways and actors when diplomacy goes digital - The e-Diplomacy Campaign "Midwives4All
}

\author{
Elin Wihlborg \\ Linkoping University, Sweden \\ elin.wihlborg@liu.se
}

\begin{abstract}
This article focuses on Midwives4All, an $e$ diplomacy campaign launched by the Swedish MFA in 2015. The campaign aims to spread knowledge about the benefits of midwives and evidence-based midwifery. Within the campaign, the Swedish MFA, and in particular its Communications Department (UD-KOM), combines e-diplomacy and networking and the campaign has become one key activity within the Swedish feminist foreign policy. It is organizing diplomacy in new ways that regards both choices of channels and the networking with inter- and nongovernmental organizations. The limited impacts of the campaign are seen as consequences of the peripheral status of the issue and the lack of systematic structures for e-diplomacy so far. In spite of this the case indicates that e-diplomacy has the potential to raise and empower both new actor groups and new issues on the diplomatic agenda.
\end{abstract}

\section{New tools for a new policy - introduction}

Diplomacy and international politics is one of the least systematized areas of politics and has even been described as anarchy [1]. However, new norms, social ideas, and identities have slowly decayed the hierarchies, and in particular gender equality is an emerging issue [2]. Such changes open for new structures and issues to be addressed on the international diplomacy agenda.

International politics and diplomacy is sues that are less formal and institutionalized than national ones have the potential to gain even more from digital media [3]. The emerging conceptualization of ediplomacy grasps the use of social media and other digital tools in the context of international and diplomatic relations [3]. Digital diplomacy and ediplomacy are used as interchangeable concepts .

The Swedish government has long had a democratic and inclusive approach in its foreign policies. The policies and development program has been focusing on issues like public health, education, equality and democracy as a key for development [4].

\author{
Anna Norstedt \\ Linkoping University, Sweden \\ annaelviranorstedt@gmail.com
}

As a formalization of this policy, the Swedish Prime Minister in 2014, in his declaration of the new government, clarified the government's feminis $t$ foreign policy. It was formulated as "Ensuring that women and girls can enjoy their fundamental human rights is both an obligation within the framework of our international commitments, and a prerequisite for reaching Sweden's broader foreign policy goals on peace, and security and sustainable development" [5]. This policy aim is in line with the in 2015 formulated UN sustainable development "Goal 5: Achieve gender equality and empower all women and girls" [6].

The Department of Communication at the Swedish MFA (UD-KOM) is in charge of developing the communicational tools needed for digital and public diplomacy. They support the diplomatic objectives to "effectively project Swedish values and political interests abroad, as well as maintaining relationships with the public and other governments" [7, pp. 168]. The Swedish MFA was as signed to implement the idea of a feminist foreign policy and this campaign became a key activity in this policy formation.

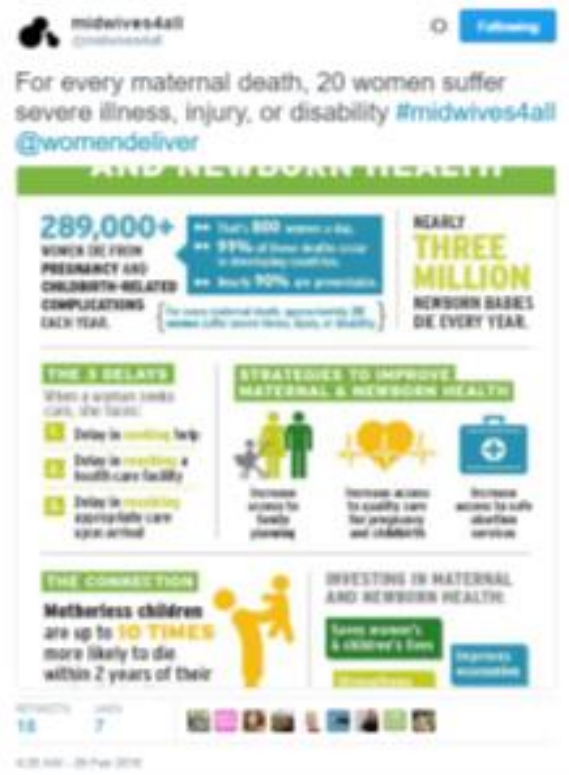

Figure 1. Screen shot from the Midwives4All Twitte raccount, published 26 Feb. 2015, 4:25 AM 
The campaign's basic arguments, as shown above, build on research presented in The Lancet's series on midwifery and UNFPAs State of the World's Midwifery Report [8].

\subsection{Aim of the paper}

The aim of the article is to analyze the campaign "Midwives4All" as a case of e-diplomacy and discuss how a feminist foreign policy can gain from new forms of diplomacy and technologies.

The paper is organized around three research questions:

RQ1: How is e-diplomacy conceptualized?

RQ2: What is the Swedish MFA's approach to ediplomacy in general and within the Midwives4All campaign in particular?

RQ3: How can e-diplomacy facilitate other is sues and actors than the traditional diplomatic actors?

This paper consists of four sections. The introduction includes a discussion on research methods and selection of the case. Secondly, theories and models in the emerging field of e-diplomacy is presented and discussed (RQ1). The third section presents the case study of "Midwives4all" and the Swedish MFA's (RQ2) approach to e-diplomacy. Finally, the case is analyzed and related to a more general discussion (RQ3).

\subsection{Grasping on-going processes - Methods and material}

The e-diplomacy campaign "Midwives4All" was launched by the Swedish MFA in February 2015, but the MFA is not the only actor as there are a number of 'nodes', i.e. external collaboration partners, connected to the campaign. The combination of the use of social media and networking so far appears to be rather unique for Swedish diplomacy and thus the case was selected to show such a process. The case is also related to a general policy change-towards feminis $\mathrm{m}$. We hereby explore the usage of social media in a very specific political setting and the integration of evidence based arguments for midwifery, which makes it interesting in several ways. The case also indicates how a relatively small country can use ediplomacy to reach out and put emphasis on a far beyond mainstream issue to "punch above their weight" in diplomacy [9]. Thus, the case was chosen because it combines e-diplomacy, networking and features of the Swedish feminist foreign policy.
The case study is grasped through an analysis of documents, places and narratives to understand gendered dimensions [10]. This includes public documents, interviews and focus groups with stakeholders, and monitoring of social media dialogues.

The social media element of the process focuses on social media activities by the Swedish MFA and its followers on the social network platforms where the Midwives4All initiative is present, i.e. Facebook, Twitter, Thunderclap, Instagram, and the Midwives4All website. The campaign's presence on social media sites has been analyzed in terms of process and effects of e-diplomacy. Two time spans have been chosen for the collection of data: 23 February - 23 March 2015 and 1 - 30 September 2015 to respectively cover the first month after the campaign was launched and the period of the Thunderclap campaign. No aggregated data on statistics has been made available, thus the analys is rather focuses on the content. The snap shots chosen to illustrate the process and its result are not representative, but should rather be seen as illustrations of the way they are arguing and presenting the issues.

The narrative of this campaign was formed through a half day focus group interview with central professional staff and diplomats managing the campaign at the Swedish MFA in March 2016. The interview provided critical and focused discussions on the framing of the campaign, its formulation, process, and challenges. The advantage of this approach is that, through discussion, the informants highlight and reflect upon issues that cannot be prepared as questions before the meeting [11]. Additional interviews have been arranged with representatives for some of the campaign's nodes.

\section{What is e-diplomacy? - Conceptualizing the key issue}

e-diplomacy is extending the meaning of egovernment into the field of communications and power relations among states in the globalized political arena. In this section RQ1 is addressed firstly by framing the field of diplomacy into contemporary social change and secondly by focusing on actors and issues, before summing it all up into an analytical model that will be used for the final analysis of the case. 


\subsection{Diplomacy in a changing world}

Diplomacy is a field in continuous transformation, relating changing national governments' intentions with the, in many ways, still vague institutional setting of anarchy in international politics. Diplomacy has been characterized as 'the master institution' of international relations [12] es sential for the conduct of interstate relations [13]. Diplomacy is one of the few international institutions that has succeeded in surviving the challenges posed by popular sovereignty and $19^{\text {th }}$ century nationalism [14]. However, there are still disagreements on what diplomacy is and the concept is evolving both in theory and practice [15].

Information and communication have always been at the core of diplomatic practices. The invention of the telegraph, for example, led to the possibility for a global communication network where messages could be sent more rapidly [16]. However, despite the significant changes the world has seen within the field of communication in more recent years, the structure of diplomacy has in many ways remained largely unchanged and based on personal meetings, often at the top-level [17]. Thus it is challenging to carry out diplomacy in today's highly interactive environment, rich in information fostered through digital technologies. This new diplomatic context has also opened for more complex and interchangeable interests and identities of actors [18].

To grasp diplomacy there is an epistemological discussion about what should be included, disputing the boundaries of what can be analyzed within the field of diplomatic studies: the distinctions of who are considered diplomats (and who are not); what diplomatic practices are (and are not) is continually under negation. A basic common conceptualization considers diplomacy as management of negotiations in international relations mainly by ambassadors and envoys [15].

There is still a weak notion of how to conceptualize the use of ICT, social media, and e-government into the field of diplomacy. There is no consensus on the use of 'e-diplomacy', and as in many other academic fields there seems to be a tendency to black box the use of technology [19].

\subsection{The networked setting of diplomacy}

The contemporary setting for diplomacy, as is our global world in general, is characterized by a more networked structure. This kind of diplomacy is characterized by three activities: communication and fact-finding, pressure activities, and advocacy. In the networked context, relationship building, management, and enhancement among state and nonstate actors becomes essential in 'networked diplomacy'[20]. There is a need for diplomatic practices to change accordingly by allowing for an approach that is less hierarchical and to some extent more casual [7]. Tradition is still important, but diplomacy is quickly being overtaken by new methods of influence and interaction. Non-state actors, and particularly NGOs, promote a sort of "parallel diplomacy' that acts like a substitute for state diplomacy [21].

ICT and social media are easy toolkits that can be used when trying to reach this goal. Yet it is important to keep in mind that the power of a technology in itself is not necessarily translated into the effect of its usage - it is rather dependent upon how successful public diplomacy organizations, diplomats, and other stakeholders are when utilizing these tools [20].

In the contemporary debate on diplomacy a post positivist approach has extended the meaning of diplomacy, encompassing a broader range of actors and at the same time problematizing the core diplomatic functions of representation and communication [15]. The use of ICTs has greatly contributed to facilitating communication between foreign ministries, MFAs, and diplomats working in the field, and has also facilitated the communication between foreign ministries and populations both home and abroad [17]. Social networking platforms have extended the number of actors and issues and has ensured e-diplomacy is here to stay [22].

Pigman [15] argues that traditional diplomatic institutions today, such as the MFAs, are increasingly likely to see themselves bypassed by other actors. Thus he concludes that the MFAs will be able to maintain their role at the core of diplomatic practice only if they are willing to function as "boundary spanners" bringing together and facilitating contact between other state and non-state actors. This case study is framed in Pigman's conclusions since we will analyze how the Swedish MFA is forming networks via social media to act as boundary spanners.

\subsection{The (e-)diplomatic actors}

Governments and their Foreign Services are the key actors in the diplomatic arena since they represent the power of a state. The increasing number of nonstate international actors in combination with the expanding diplomatic agenda and international order is blurring the boundaries of diplomacy [13, 23].

Today there is a wider range of actorsmultilateral institutions based in the UN such as the World Health Organization (WHO), transnational firms, and also a wide range of nongovernmental 
organizations (NGOs). The latter group in particular presents new policy fields like climate negotiations, for example [24]. It is argued that NGOs have more leeway when it comes to fact-finding than states do, especially when it comes to promoting human rights and mapping related policies - situations where states may be unwilling to report them openly or to try to correct human rights abuses [21].

Diplomatic actors and processes can be as signed to two core functions/activities: representation and communication. Representation has to do with the notion of the diplomatic actor posing questions about how the diplomatic actor represents itself to other actors with whom it would like to establish and/or maintain a relationship. Diplomatic communication traditionally takes place between individuals that are entrusted with representing or speaking for collective entities, such as nation-states or multilateral organizations [13].

The actors failing to adapt to the networked environment risk falling behind, thus losing trust and as a consequence also losing influence and legitimacy [7]. The stakeholder's willingness to interact around the cause as a way of cooperatively achieving change is essential to the influence and reach of an ediplomacy campaign. Networking with likeminded actors and making use of their audiences may help [20]. The use of digital tools develops new practices in the governmental and diplomatic contexts. In these processes it is critical that changes are formed to promote trust and legitimacy [25].

E-diplomacy contributes to a wider inclusion of actors since the barriers to participate erodes. Yet, the technical revolution has just started to change the ways in which MFAs do business [17]. Even if digital technologies already have changed the ways in which individuals manage their social relations, firms manage their businesses, and states govem themselves, the field of diplomacy is lagging behind [26].

It has also been shown that it is difficult to get people and stakeholders in particular to be active in social media debates on international policy making issues. Johannessen et.al. [27] conclude that the salience level of stakeholders is crucial for their participation, in that mainly actors who are less salient will use every available medium to gain influence. Global debates and participation on international issues has developed beyond the diplomatic and international channels since new actors have new arenas to raise issues of interest [28].

\subsection{The (e-)diplomatic issues}

Badie [21] notices that in line with the more open digital agenda for diplomacy there is also a raise of social issues, such as human rights. This has transformed traditional diplomacy into intersocial diplomacy where state and non-state actors, via diplomacy, manage the gap separating civil societies from each other and makes diplomacy social rather than political. Intersocial diplomacy has the potential to bridge societies in a way that makes no one appear as the legitimate representative of a social system. The diplomacy is then identified through the particular issue at stake, the concerned population, and the involved actors rather than traditional interstate diplomacy where professional diplomats are the key actors. Interaction between intersocial and interstate diplomacy is argued to be necessary for successful future global governance [21]. The essential transformation of the realm of communication in the network society [29] "finally" appears to also influence diplomacy. E-diplomacy has the potential, as do other e-government practices, to open for different forms and use of information and knowledge sharing while at the same time promoting transparency [30].

When e-diplomacy shifts hierarchical structures into an openness for citizens and grassroots [7], it also has to have an openness to new issues. Social media can be seen as a new tool in the diplomatic toolbox in the context of transformative development of international politics and in bringing in 'ordinary people' to make their voices heard [3].

\subsection{Meanings of e-diplomacy}

E-diplomacy includes partly new actors and addresses partly new issues, as shown above. It has emerged from a government only business that has an ambition to maximize engagement with increasingly interconnected foreign publics focusing on dialogue [31].

E-diplomacy can also be seen as a practice within the contemporary emerging context of soft power [32] by enabling communication in a multidirectional fashion between diplomats and foreign publics [22]. Thus, a state's relative soft power will be dependent on whether others perceive its policies as legitimate and if the state's national ideas and values in practice are represented by its officials. It further builds on how attractive a county's culture, political values and foreign policies are perceived [32].

Even if e-diplomacy affects all forms of diplomatic activities, public diplomacy, i.e. diplomatic engagement with the public is the diplomatic 'area' 
most affected by these changes [33]. Traditional oneway communication, from diplomatic services to domestic or foreign publics, has been replaced by opportunities for two-way interaction between diplomatic services and domestic and foreign publics [16]. Critics of e-diplomacy, however, claim that social media just provides new tools for propaganda. The openings for two-way communication and dialogue are not used by governments, who rather say the same things they have always said, except they now do it in a tweet or Facebook post [9]. There is also criticism towards what Nye [32] calls 'the paradox of plenty" - where "plentiful information leads to scarcity of attention".

There are a number of online platforms that may be used when practicing e-diplomacy and these are useful in different ways for different purposes since none of them are designed for e-diplomacy as such [34]. Deruda suggests a four-step path to develop a social media roadmap before launching an ediplomacy campaign: 1) monitor social media and listen to online conversations, 2) open accounts on different platforms and then start to publish valuable content, 3) stimulate interaction with and among followers and actively participate in conversations, and 4) involve citizens in processes of decisionmaking through social media.

e-diplomacy can also be conceptualized by focusing on the effectiveness of the use of social networking platforms for diplomatic communication and purposes of e-diplomacy campaigns [3]. Bjola and Jiang [3, pp. 74] argue that "the key to understanding the effectiveness of a particular strategy of ediplomacy rests with its capacity to move beyond information dis semination, and to create conditions for two-way conversation between diplomats and the foreign public at large". The framework focuses on agenda-setting, presence-expansion, and conversation-generating.

Each of the dimensions in Bjola and Jiang's framework asks a question to evaluate the effectiveness of digital diplomatic efforts: 1) Agendasetting: what kind of information is being used to inform and influence the public? 2) Presenceexpansion: how far can this influence reach? 3) Conversation-generating: through what kind of mechanis $m$ is influence exerted?

The development of a wide variety of social networking platforms brings with it opportunities to connect with foreign publics and states directly without relying on, for example, traditional media as middleman. New diplomatic stakeholders have emerged and there are advantages for states in cooperating with these, especially as NGOs in some cases may have more leeway. Effective e-diplomacy, following Bjola and Jiang [3], succeeds in putting the issue at hand on the agenda, by reaching large audiences not solely consisting of states, and generating conversation. This may in turn spark incremental shifting through grassroots or interest organizations.

\subsection{An analytical frame for e-diplomacy}

To summarize this section: e-diplomacy takes place in a more networked international and diplomatic context. It is allowing for new actors and is sues through digitalization and in particular social media and the emerging practices of soft power. It also opens for discussions on new issues and the involvement of other actors in processes of decisionmaking. The four main steps of such processes are listening, getting on-line, stimulating interaction, and becoming involved in decisions [34]. In all these steps actors and issues can be analyzed.

The effects of such process on diplomacy and power can be evaluated by estimating agenda setting, presence expansion and convers ation generation [3].

\section{The case study: "Midwives4all" an e- diplomacy campaign by the Swedish MFA}

Sweden has a tradition of making use of new communication technologies for political purposes. In 2013 Carl Bildt, Sweden's Minister for Foreign Affairs at the time, announced that all Swedish embassies were to establish presence on Facebook and Twitter [35]. Since then Sweden's e-diplomatic efforts have continued to develop. The Swedish MFA has started to cooperate with other stakeholders to "break through the noise" and create content. When it comes to communicating Swedish political values the MFA has started to adopt a more active approach [7]. The Swedish MFA cooperates with other actors within the framework of the Midwives4All campaign. Among these 'nodes' are actors such as The Lancet, Sida (the Swedish International Development Cooperation Agency), the International Confederation of Midwives (ICM), and the Swedish Association of Midwives. This means that there is an essential network of different types of actors supporting the campaign.

\subsection{The initiative of the campaign}

Issues like democracy, gender equality, and women's participation have been a part of Swedish 
foreign policy since the 1960s [4]. Furthermore, Sweden has a tradition of promoting Sexual and Reproductive Health Rights (SRHR), regardless of the political orientation of the government. The current Social Democrat led government launched the feminist foreign policy but there are many examples of SRHR initiatives launched by previous centre-right governments. For example, during 2005-2010 Sida, through Lund University, gave eight international training programs where one-month courses were taught to 220 foreign midwives and obstetricians. The participants then led development projects on the is sue in their home countries [36]. Furthermore, in 2013 the then Prime Minister Reinfeldt raised the importance of equality and SRHR at the UNGA's head of states meeting [36].

Seen in this light the focus on midwifery in this campaign is not a long shot. Midwives4All fits well with the Swedish feminist foreign policy as it seeks to improve the situation for disadvantaged women. Elucidating midwifery, a health service that primarily serves to improve women's health, is thus an essential part of the implementation of the feminist foreign policy.

The initiative started out as a collaboration between The Lancet, the Swedish Embassy in London, and the MFA as a way of spreading the word on The Lancet's midwifery series published in 2014. Since then a number of other actors have joined the campaign as nodes. It shall be noted that the Department of Communication at the Swedish MFA had the idea of a campaign promoting midwifery before the election. Thus, although the campaign fits well with Sweden's feminist policies, it was not planned with the purpose of being a feminist foreign policy effort. Although it is a campaign launched by the Swedish MFA the campaign is not promoting Swedish midwifery practices. Swedish examples are not used as benchmarks, rather it is the research presented in the Lancet that serve as examples. By not framing the campaign as a Swedish campaign the MFA believes it has better chances of reaching out [37].

Several Swedish Ministers, including the Prime Minister and the Minister for Foreign Affairs, have highlighted the campaign as a key activity connected to the Swedish feminist policy.

Through Miwives4All the MFA hopes to contribute to increased awareness about and advocacy for midwifery [37]. Generally speaking, midwifery is not a politically sensitive is sue, rather it is seen by the Swedish MFA as something everyone can support, no matter which political beliefs one might have [37]. The MFA sees Midwives4All as a successful example of how e-diplomacy can contribute to increased knowledge and raise awareness about a field where Sweden has large amounts of experience [38].

\subsection{The running of the campaign and selection of social me dia channels}

It is the Department of Communication at the Swedish MFA that is in charge of developing the communicational tools needed for its staff to be successful in fulfilling the Swedish diplomatic objectives to "effectively project Swedish values and political interests abroad, as well as maintaining relationships with the public and other governments" [7]. The MFA deems it important to have presence in the communication channels used by its audiences [37]. The campaign is present on a number of social media platforms: Facebook, Twitter, Thunderclap, and Instagram, and it also has its own web-page. The Swedish MFA uses the tag @midwives4all for the Midwives4All campaign and has launched \#midwives 4all. The hashtag may be used by everyone who deems it relevant, however it should be noted the use of the hashtag does not necessarily have be in line with what its 'creator' intended as hashtags can be 'hijacked' and used for other purposes. Below is an example of what the messages conveyed may look like:

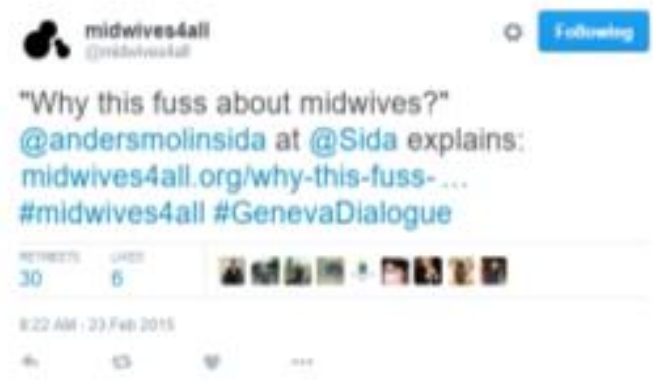

Figure 2. Screen shot from the Midwives4All Twitte raccount, published 23 Feb. 2015, 8:22 AM.

The Midwives4All web-page serves as the hub for all of the other social media platforms used within the campaign. It is frequently referred and linked to, both in the Midwives4All biographies on different social media and also in the actual messages. All of the campaign's nodes have their own login credentials to the web-page, thus allowing for actors other than the MFA to be the sender. During the timespan studied 46 blog posts were made.

The table below shows the number of posts made during the selected time-spans by governmental (the MFA, the Minister for Foreign Affairs, Swedish 
ambassadors, Sida), inter-governmental (UNFPA), and non-governmental organizations (for example Doctors Without Borders, The Lancet, ICM). The table indicates that despite governmental actors and NGOs posting the same number of posts, the average number of likes are far higher on the governmental posts. This might indicate that messages by governmental actors are seen as more 'credible' than the ones made by NGOs.

Table 1. Posts by different types of actors

\begin{tabular}{|l|l|l|}
\hline \multicolumn{1}{|c|}{ Type of Actor } & \multicolumn{1}{|c|}{$\begin{array}{c}\text { Number } \\
\text { of posts }\end{array}$} & $\begin{array}{c}\text { Average } \\
\text { number of } \\
\text { likes? }\end{array}$ \\
\hline Governmental & 11 & 315,9 \\
\hline Intergovernmental & 1 & 0 \\
\hline Non-Governmental* & 11 & 107,27 \\
\hline
\end{tabular}

* Universities and research is here included in the NGO category .

\subsection{Networking for social change}

As discussed above, diplomacy has become more intersocial in character. From a Swedish perspective there is an understanding that taking initiatives to kickstart processes is important in order to generate further engagement and interaction. By inviting other stakeholders to take part in networks and driving discussions on topics of (future) concern, content that can be used in both online and offline contexts is created while at the same time, new relationships may be established [7]. This mindset has been used in the Midwives4All campaign as the MFA for the most part has chosen to work with external actors, rather than just using the Swedish embassies as partners and disseminators of the campaign's messages. This allows for a more 'flat' network structure [37]. Still, some of the Swedish embassies located in developing countries where midwifery practices can be improved have been invited by the MFA to participate in the campaign.

One example was the Swedish Embassy in Uganda, which participated in the campaign during 2015. The embassy's campaign had three components: it used high profile Ugandans, including the Ugandan First Lady, as 'ambassadors' for midwifery; it engaged mass media and held an orientation day on midwifery for journalists; and it organized events to create a platform to promote Midwives4All and its activities. Young Ugandan bloggers were invited to raise awareness on midwifery and to promote the midwife profession. The Embassy and the MFA sees the campaign as successful, especially when it comes to the efforts made to create advocacy [37, 39]. However, the long-term impacts of the campaign are yet to be determined.

The MFA has also founded an award for excellence in midwifery that is given to working midwives for their contributions to the field. The awardees are nominated by the ICM and the Swedish Association of Midwives. The stories of the awarded midwives are shared on the campaign's social media.

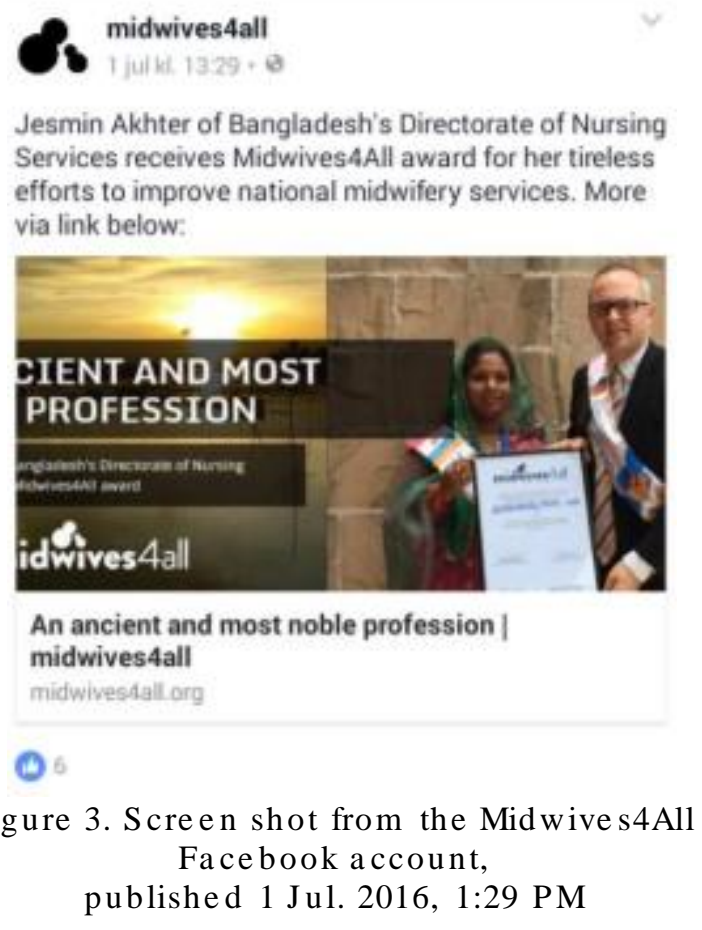

\subsection{Lessons learned by the case study}

To conclude this section we would like to highlight three aspects of the campaign: its timing, its participants, and the choice of midwifery as the campaign's focus.

The timing of the campaign is good, if not perfect, as it fits with the feminist foreign policy launched in 2014. Yet, it was planned before the election in 2014 and should hence not be seen as a political initiative aimed at pursuing a feminist foreign policy.

The participants in the campaign, i.e. the nodes, have been chosen based on their interest in and knowledge about midwifery. This means that their knowledge contributes to increasing the legitimacy of the campaign. Furthermore, the nodes "lend" their audiences to the MFA, thus expanding the potential reach of the campaign and its messages.

The is sue is not a very sensitive one, as midwifery is not a controversial topic. It would have been different if the MFA had chosen to focus on the right to free and safe abortions. The case of women's 
reproductive health is already on the agenda and is made legitimate through the UNs focus on similar issues. Furthermore, the campaign is not targeting countries with whom Sweden has important diplomatic relations with. Thus the campaign is not risking any high-maintenance diplomatic relations.

\section{How e-diplomacy can facilitate new issues and actors - Analysis}

In this section our analysis of the process builds on Deruda's four-step path of developing a social media roadmap for e-diplomacy efforts. The assessment of the campaign's effectiveness builds on Bjola and Jiang's three-dimensional framework.

\subsection{The process of Midwives4All}

In this section we focus on the process of ediplomacy by following Deruda's four steps presented in section 2.5 .

The Swedish MFA did monitor and listen to the discussion in social media before launching Midwives4All. They did so as they wanted to see how midwifery was discussed in these channels [37]. The Lancet's series on Midwifery was the take-off which the MFA could make use of to communicate their feminist policies. Thus, there is a win-win: the MFA gets evidence based information on midwifery and The Lancet's messages reach a larger audience. Ideas of promoting the importance of midwifery were on the agenda before the general policy statement of a feminist foreign policy, as we found out through the focus groups [37].

The second step of the process was that MFA opened Midwives4All accounts on different platforms. As the campaign was already prepared six months before its launch [37], the MFA was ready to start publishing valuable content right away. The initiative is still active on most of the platforms chosen, although its Instagram account was only active for one day.

Interaction with and among followers is critical both for the proceeding of the process and its effects [3]. It is unclear why the Swedish MFA does not appear to succeed in this aspect. The early relations to the Lancet and the content of the journal's midwifery series opened for more interaction on the issue in the campaign's channels, yet barely any discussion was generated. Although midwifery receives some political attention, for example through the SDGs, the issue is still a peripheral issue far from the top of the political international agenda.

Another potential reas on for the low interaction in the process is that there is no clear decision making to address. There is no specific agenda nor any time plan for decisions on midwifery for all, despite the SDGs . This process is supposed to go on through bottom-up incremental changes and thus the effects may not appear on this general level.

\subsection{Effects of the Midwives4All campaign}

The analysis through the process perspective showed several constraints that confuse the impact of the effects. Thus we will extend the discussion on the effects partly beyond the campaign based on Bjola and Jiang's three-dimensional framework.

Firstly, it is obvious that midwifery, or the lack thereof, affects groups with low positions in society. Disadvantaged women are far from the top level diplomacy agenda. Yet lowering the maternal mortality rate is a part of the SDGs and there is clear evidence that midwifery is a vital tool for doing so [40]. The messages used in the campaign are informative and based on research from evidencebased midwifery rather than political consequences like the need for spending on public health care.

Secondly, focus on presence expansion can be seen as effective by the network of actors that has been established including medical professionals, policy makers, and some NGOs. As a coordinator of the nodes the Swedish MFA reached out to wider audiences. This is because the nodes' audiences, through the campaign, became the MFA's audiences. Without the nodes the reach of the campaign is more likely to have been limited to the followers of the MFA and the Swedish embassies. Thus the MFA succeeded in finding a way to communicate beyond their own regular audiences.

Thirdly, the reach into new audiences has also increased the conversation generating effects. But here we would also like to highlight other activities that took place in relation to the same issue, like the educational programs for midwives. The internal effects within the MFA may be constrained by its still hierarchical and bureaucratic organization that is not adjusted to the networking and informal character of social media. This is also indicated by the fact that followers appear rather reluctant to comment or initiate dialogue themselves. 


\section{Concluding remarks}

This paper has discussed if and how e-diplomacy opens for other is sues and actors on the foreign policy agenda. The main conclusion drawn from the case study is that even if the issue of midwifery is not as present on the agenda as other issues, this is probably the only way to reach out with a 'new' issue regarding a disadvantaged group.

The limited impacts of the campaign can be interpreted in several ways. Firstly, the selection of a quite peripheral policy issue decreases the power impact and status of the campaign. Scarce midwifery affects poor women in developing countries, and a midwife is in many countries still considered a low status profession far from the main diplomatic issues. In spite of this, there are indications that e-diplomacy has the potential to raise and empower both new actor groups and new issues on the diplomatic agenda.

There is also a need to find new ways to get the feminist foreign policy on the agenda and also to be able to communicate with other types of stakeholders and reach out with more soft power. The analysis shows that legitimacy can be gained by relying on medical evidence and the network of other actors than only the MFA. The MFA acted as a boundary spanner in this respect.

e-diplomacy, in the ways as discussed here, may provide good tools for other voices heard. This case showed that even the voices not on-line themselves poor women in developing contexts - got a voice and their living conditions came up as diplomatic issues. In the future e-diplomacy has the potential to make many more voices heard on the international agenda, thus expanding the presence of and generating conversations on issues of inequalities and social injustice. Hopefully this is done in ways that address the UN's sustainability goals, improving the life conditions for children, mothers, and the globe.

\section{References}

[1] B. Buzan, C. Jones and R. Little, The Logic of Anarchy, Columbia University Press, 1993.

[2] A. Brysk and A. Mehta. "Do rights at home boost rights abroad? Sexual equality and humanitarian foreign policy." Journal of Peace Research 51, pp.97-110, 2014.

[3] C. Bjola and L. Jiang, "Social Media and Public Diplomacy: A Comparative Analysis of the Digital Diplomatic Strategies of the EU, US and Japan in China", in C. Bjola and M. Holmes (eds), Digital Diplomacy: Theory and Practice, Routledge, 2, pp. 71-88, 2015.
[4] A.M. Ekengren, "How Ideas Influence DecisionMaking: Olof Palme and Swedish Foreign Policy 19651975", Scandinavian Journal of History, 36(2), pp. 117-134, 2011.

[5] Swedish Government web paper "Feminist Foreign Policy", $\quad$ http://www.government.se/governmentpolicy/feminist-foreign-policy/

[6] UN, "Goal 5: Achieve Gender Equality and Empower All Women and Girls", www.un.org/sustainabledevelopment/gender-equality/

[7] J. Pelling, "When Doing Becomes the Message: the Case of the Swedish Digital Diplomacy", in C. Bjola and M. Holmes, Digital Diplomacy: Theory and Practice, , pp. 164180, Routledge, 2015.

[8] Midwives4All, "About",
www.midwives4all.org/about

[9] A. Sandre, Digital Diplomacy: Conversations on Innovation in Foreign Policy, Rowman \& Littlefield, 2015.

[10] A. Kronsell "Methods for Studying Silences: Gender Analy sis in Institutions of Hegemonic Masculinity", in B.A. Ackerly, M. Stern and J. True (eds.), Feminist Methodologies for International Relations, pp. 108-129, Cambridge University Press, 2006.

[11] V. Wibeck, M. Dahlgren \& G. Oberg, Learning in Focus Groups: An Analytical Dimension for Enhancing Focus Group Research. Qualitative Research, 7(2), pp. 249267, 2007.

[12] M. Wight, Power Politics, Leicester University Press, 1978.

[13] C. Jönsson, "Diplomacy, Bargaining and Negotiation", in W. Carlsnaes, T. Risse and B.A. Simmons, Handbook of International Relations, SAGE Publications, pp. 212-325, 2002.

[14] P. Sharp, "For Diplomacy: Representation and the Study of International Relations", International Studies Review, 1(1), pp.33-57, 1999.

[15] G.A. Pigman, "Debates about Contemporary and Future Dip lomacy", in P. Kerr and G. Wiseman, Diplomacy in a Globalizing World: Theories and Practices, Oxford University Press pp. 68-84, 2012.

[16] J. Kurbalija, "The Impact of the Internet and ICT on Contemporary Diplomacy", in P. Kerr and G. Wiseman, Diplomacy in a Globalizing World: Theories and Practices, pp. 141-159Oxford University Press, 2012.

[17] M. Holmes, "Digital Diplomacy and International Change Management", in C. Bjola and M. Holmes, Digital Diplomacy: Theory and Practice, pp. 13-32, Routledge, 2015. 
[18] J.P. Singh, 'The Power of Diplomacy: New Meanings, and the Methods for Understanding Digital Diplomacy", in C. Bjola and M. Holmes, Digital Diplomacy: Theory and Practice, pp. 181-198, Routledge, 2015.

[19] B. Latour, "Technology is Society Made Durable", The Sociological Review, 1990 38(1), pp. 103-131.

[20] S.E. Park and Y.S. Lim, "Information Networks and Social Media Use in Public Diplomacy: A Comparative Analysis of South Korea and Japan", Asian Journal of Communication, 2014 24(1), pp. 79-98.

[21] B. Badie, "Transnationalizing Diplomacy and Global Governance", in P. Kerr and G. Wiseman, Diplomacy in a Globalizing World: Theories and Practices, pp. 85-102, Oxford University Press, 2012.

[22] S. Sotiriu, "Digital Diplomacy: Between Promises and Realities", in C. Bjola and M. Holmes, Digital Diplomacy: Theory and Practice, Routledge, New York, 2015, pp. 33-51.

[23] K.Hamilton and R. Langhorne, The Practice of Diplomacy: Its Evolution, Theory and Administration, Routledge, 1995.

[24] N. Nasiritousi, M. Hjerpe and B.O. Linnér, "The Roles of Non-State Actors in Climate Change Governance: Understanding Agency Through Governance Profiles", International Environmental Agreements: Politics, Law and Economics, 2016 16(1), pp. 109-162.

[25] E. Wihlborg, "Legitimate E-Government--Public EServices as a Facilitator of Political Legitimacy", $47^{\text {th }}$ Hawaii International Conference on System Sciences, IEEE, 2014.

[26] C. Bjola, "Introduction: Making Sense of Digital Diplomacy", in C. Bjola and M. Holmes, Digital Diplomacy: Theory and Practice, pp. 1-9, Routledge, 201.

[27] M.R. Johannessen, Ø. Sæbø and L.S. Flak, "Social Media as Public Sphere: A Stakeholder Perspective", Transforming Government: People, Process and Policy, 10(2), ahead of print, 2016.

[28] C. Padovani and E Pavan, "Actors and Intractions in Global Communication Governance: the Heuristic Potential of a New Network Approach", in R. Mansell and M. Raboy, The Handbook of Global Media and Communication Policy, pp. 543-563,2011.

[29] M. Castells, "The Network Society: from Knowledge to Policy ", in M. Castells and G. Cardoso, The Network Society: From Knowledge to Power, Center for Transatlantic Relations, pp.3-22, 2005.

[30] J. Fountain, "Central Issues in the Political Development of the Virtual State", in M. Castells and G. Cardoso, The Network Society: From Knowledge to Power, Center for Transatlantic Relations, pp. 149-182, 2005.
[31] J. Melissen, The New Public Diplomacy: Soft Power in International Relations, Palgrave Macmillan, 2005.

[32] J. Nye, The Future of Power, Public Affairs, 2011.

[33] J. Melissen, "Public Diplomacy", in P. Kerr and G. Wiseman, Diplomacy in a Globalizing World: Theories and Practices, , pp. 192-2080xford University Press, 2012.

[34] A. Deruda, The Digital Diplomacy Handbook: How to Use Social Media to Engage with Global Audiences, Create Space Independent Publishing Platform, 2015.

[35] C. Christensen, "Discourses of Technology and Liberation: State Aid to Net Activists in an Era of "Twitter Revolutions"', The Communication Review, 14(3), pp. 233253, 2011.

[36] Regeringskansliet [Swedish Government Offices], "Från Befolkningsfrågor till SRHR", [From population issues

to

SRHR],http://www.regeringen.se/contentassets/d0f27ea3fe 59435d9c3dbbfb2efd3ed9/fran-befolkningsfragor-till-srhr--sverige-globala-engageman g-i-sexuell-och-reproduktivhalsa-och-rattigheter

[37] Focus group interview by the Author at the Swedish MFA, 3 March 2016.

[38] R. Dyab, "Fler ambassader deltar i Midwives4All" [More Embassies Takes Part in Midwives4All], sent to the authors by UD-KOM

[39] Embassy of Sweden in Uganda, "Midwives4All Uganda: Key Results and Lessons Learned", PDF sent to the authors by the Embassy.

[40] M.J. Renfrew et.al., "Midwifery - an Executive Summary for the Lancet's Series", http://www.thelancet.com/pb/assets/raw/Lancet/stories/seri es/midwifery/midwifery exec summ.pdf 